\title{
A lipoxygenase with dual positional specificity is expressed in olives (Olea europaea L.) during ripening.
}

Cynthia Palmieri-Thiers ${ }^{\mathrm{a}}$, Stéphane Canaan $^{\mathrm{b}}$, Virginie Brunini ${ }^{\mathrm{a}}$, Vannina Lorenzi $^{\mathrm{a}}$, Félix Tomi ${ }^{\mathrm{c}}$, Jean-Luc Desseyn ${ }^{\mathrm{d}}$, Ulrike Garscha ${ }^{\mathrm{e}}$, Ernst H. Oliw ${ }^{\mathrm{e}}$, Liliane Berti ${ }^{\mathrm{a}}$, Jacques Maury ${ }^{\mathrm{a}, *}$

a Université de Corse, CNRS UMR6134 SPE, Laboratoire de Biochimie et Biologie Moléculaire Végétales, campus Grimaldi, BP52, 20250 Corte, France

${ }^{\text {b }}$ Laboratoire d'Enzymologie Interfaciale et de Physiologie de la Lipolyse, CNRS, UPR 9025, 31 chemin Joseph Aiguier 13402 cedex 20, Marseille, France

c Université de Corse, CNRS UMR6134 SPE, Equipe Chimie et Biomasse, route des Sanguinaires, 20000 Ajaccio, France

${ }^{\mathrm{d}}$ INSERM U837-JPARC, 1 place de Verdun, 59045 Lille, France.

e Division of Biochemical Pharmacology, Department of Pharmaceutical Biosciences, Biomedical Center, Uppsala University, SE-751 24 Uppsala, Sweden.

\section{* Corresponding author}

J. Maury, Université de Corse, CNRS UMR6134, campus Grimaldi, BP52, 20250 Corte, France. Fax : +33 495610 551. Tel : +33 495450069

E-mail address : maury@ univ-corse.fr

Running title: A lipoxygenase with dual positional specificity in olives

Keywords: lipoxygenase, olive, development, ripening, aroma 
Note: The nucleotide sequence reported is in the GenBank database under the accession number EU678670 


\begin{abstract}
Plant lipoxygenases (LOXs) are a class of widespread dioxygenases catalyzing the hydroperoxidation of polyunsaturated fatty acids. Although multiple isoforms of LOX have been detected in a wide range of plants, their physiological roles remain to be clarified. With the aim to clarify the occurrence of LOXs in olives and their contribution to the elaboration of the olive oil aroma, we cloned and characterized the first cDNA of the LOX isoform which is expressed during olive development. The open reading frame encodes a polypeptide of 864 amino acids. This olive LOX is a type-1 LOX which shows a high degree of identity at the peptide level towards hazelnut $(77.3 \%)$, tobacco $(76.3 \%)$ and almond $(75.5 \%)$ LOXs. The recombinant enzyme shows a dual positional specificity, as it forms both 9- and 13hydroperoxide of linoleic acid in a 2:1 ratio, and would be defined as 9/13-LOX. Although a LOX activity was detected throughout the olive development, the 9/13-LOX is mainly expressed at late developmental stages. Our data suggest that there are at least two Lox genes expressed in black olives, and that the 9/13-LOX is associated with the ripening and senescence processes. However, due to its dual positional specificity and its expression pattern, its contribution to the elaboration of the olive oil aroma might be considered.
\end{abstract}




\section{Introduction}

Lipoxygenases (LOX, EC 1.13.11.12) are non-heme iron-containing fatty acid dioxygenases found in eukaryotes and in a few prokaryotes [1-3]. LOXs catalyse the regioand stereo-specific dioxygenation of polyunsatured fatty acids (PUFAs) with a cis,cis-1,4pentadiene structure [1-4]. Based on the positional specificity of the dioxygen insertion using linoleic acid as a substrate, plant LOX isoenzymes are grouped into 9-LOX and 13-LOX types [5]. However, a few non-traditional plant LOXs can oxygenate at C-9 and C-13 positions and produce both 9-hydroperoxy and 13-hydroperoxy positional isomers. Hydroperoxidation products derived from LOX activity are subsequently metabolized into compounds such as jasmonic acid, methyl jasmonate, volatile aldehydes, and conjugated dienoic acids. These compounds are involved in seed germination, plant growth and development, senescence, and in the plant defence response to wounding and both insect and pathogen attack [6,7]. Plants express numerous LOX isoforms that can be distinguished by their expression pattern, subcellular location and substrate specificity $[5,6]$. However, physiological functions of specific LOX isozymes are not all elucidated.

LOXs are also a great interest in food science because hydroperoxides and free radicals resulting from LOX activity can exert deleterious effects on nutritionally important compounds such as essential PUFAs. LOXs also have a role in the production of volatiles molecules that can positively or negatively influence the flavour and aroma in many plant products [8].

In olive fruit, the LOX pathway is responsible for the production of desirable organoleptic properties that differentiate virgin olive oil from other vegetable oils. Angerosa et al. [9] and more recently Dhifi et al. [10] have reported that the qualitative and quantitative composition of the olive oil aroma is tightly dependent on the enzymatic store involved in the 
LOX pathway which is linked to fruit ripening. Thus, Donaire et al. [11] and Salas et al. [12] have reported a low LOX activity in green olives harvested at the initial developmental stages which decreased thereafter. Recently, the existence of several olive LOX isoforms was reported: a LOX isoform was purified from mature olives (black) harvested at the late developmental stage, which produced exclusively 13-hydroperoxides of linoleic and linolenic acids [13]; two LOX isoforms, with different thermal stabilities, were detected in immature olives (green) of the early developmental stage, which might be involved in the formation of the volatile compounds of the olive oil aroma [14]. Besides these isoforms, there is likely an uncharacterized isoform responsible for 9-hydroperoxides produced by olive LOX crude extract [15].

As LOX enzymes likely influence the organoleptic features of olive oil and in order to better understand the implication of individual LOX isoforms, we looked for new LOX enzymes. Here we report for the first time the cloning and the biochemical characterization of an olive fruit LOX isoform that is expressed at the late developmental stage and that oxygenates linoleic acid at C-9 and C-13 positions in a 2:1 ratio.

\section{Materials and methods}

\subsection{Plant material}

Olives (Olea europaea L., Leccino variety) were randomly picked up every two weeks from 8 to 32 weeks after flowering (WAF) from the experimental field of the INRA-CIRAD (Corsica, France). The olives were stoned, the pulp was immediately frozen in liquid nitrogen and stored at $-80^{\circ} \mathrm{C}$ until used. 


\subsection{RNA extraction and Northern blot analysis}

Total RNA was extracted from olive pulp as described by Hernández et al. [16]. Ten micrograms of total RNA were fractionated on a $1 \%$ formaldehyde gel according to Sambrook et al. [17] and transferred to Hybond N membrane (Amersham). Two O. europaea LOX probes, the LOX probe1 (775 bp long, Fig. 1) and the LOX probe2 (RT-PCR product 4, wich is 663 bp long, containing the 3'-UTR of the cDNA clone, Fig. 1) were radiolabeled with $\left[\alpha_{-}{ }^{32} \mathrm{P}\right] \mathrm{dCTP}$ (Perking Elmer) using the random primed DNA labelling kit (Roche) and subsequently used for Northern blot analysis.

\subsection{DNA extraction and Southern blot analysis}

Genomic DNA was extracted from fresh young leaves of the Leccino variety using the method described by Saghai-Maroof et al. [18] with some modifications [19].

Genomic DNA (about $10 \mu \mathrm{g}$ ) was cleaved with BamHI, EcoRI or XhoI restriction enzymes, fractionated on $1 \%$ agarose gel and transferred to Hybond $\mathrm{N}$ membrane (Amersham). Hybridizations were carried out using radiolabeled $O$. europaea LOX probes (the LOX probe1 and LOX probe2) according to Sambrook et al. [17].

\subsection{Reverse transcription (RT) PCR analysis}

Reverse transcription was performed using up to $5 \mu \mathrm{g}$ of total RNA extracted from mature olives (30 WAF, black stage), oligo(dT) 18 primer and the PowerScript reverse transcriptase (Clontech) according to the manufacturer's instructions. The first stand cDNA was used as template in PCR experiments with degenerated (Lox(1+3)a: 5'-ccntaygengyngaygg, 
Lox(1,2)bis: 5'-aarttnacngcngcrtg, Lox(1+3)b: 5'-acngayganganttygc, Lox1c: 5'ggnacngtngtnatgatg, where $\mathrm{y}=\mathrm{c}$ or $\mathrm{t}, \mathrm{r}=\mathrm{a}$ or $\mathrm{g}, \mathrm{n}=\mathrm{a}, \mathrm{t}, \mathrm{g}$ or $\mathrm{c}$ ) and/or specific (Loxc: 5'agtagtcctgtacccatg, Loxg: 5'-cctgccaacatctctctcgcgaat, Loxa: 5'-ggagaactagtcgactcc) primers designed from conserved amino acid sequences of known plant LOXs and during the present study, respectively. The primer combinations $\operatorname{Lox}(1+3) \mathrm{a} / \operatorname{Lox}(1,2) \mathrm{bis}, \operatorname{Lox}(1+3) \mathrm{b} / \operatorname{Loxc}$, Lox1c/Loxg and Loxa/oligo(dT) were used to amplify the RT-PCR product1, RT-PCR product2, RT-PCR product3 and RT-PCR product4, respectively (Fig. 1). The PCR conditions were as follows: $94^{\circ} \mathrm{C} 2 \min \left(1\right.$ cycle); $94^{\circ} \mathrm{C} 30 \mathrm{~s}, \mathrm{~T}_{\mathrm{M}}$ (depending of the primer sequences $) 1 \min , 72^{\circ} \mathrm{C} 3 \min (30$ cycles $) ; 72^{\circ} \mathrm{C} 7 \min (1$ cycle $)$.

\subsection{5' Rapid amplification of cDNA ends (RACE) procedures}

The 3'/5' RACE $2^{\text {nd }}$ Generation kit (Roche) was used to synthesize first-strand cDNA from total RNA ( $2 \mu \mathrm{g}$ ) of mature olives (30 WAF, black stage) with the specific primer Loxj: 5'caggatcgccattgatggaac in accordance with the manufacturer's instructions. Five microliters of poly(dA)-tailed first-strand cDNA were used as template in PCR reaction with a nested specific primer Loxl: 5'-gagctgcagagacacettttggec and the oligo(dT)-anchor primer. The PCR conditions were as follows: $94^{\circ} \mathrm{C} 3 \mathrm{~min}, 43^{\circ} \mathrm{C} 2 \mathrm{~min}, 72^{\circ} \mathrm{C} 2 \mathrm{~min}(1$ cycle $) ; 94^{\circ} \mathrm{C} 30 \mathrm{~s}, 65^{\circ} \mathrm{C} 1$ $\min , 72^{\circ} \mathrm{C} 2 \min (20$ cycles $) ; 94^{\circ} \mathrm{C} 30 \mathrm{~s}, 43^{\circ} \mathrm{C} 1 \min , 72^{\circ} \mathrm{C} 2 \min (25$ cycles $) ; 72^{\circ} \mathrm{C} 7 \min (1$ cycle). A $1 \mu \mathrm{L}$ sample of the primary amplification product was further amplified by a second PCR reaction with the nested specific primer Loxm: 5'-actcatgaactcgatcaagaa and the PCR anchor primer. The PCR conditions were as follows: $94^{\circ} \mathrm{C} 3$ min $(1$ cycle $) ; 94^{\circ} \mathrm{C} 30 \mathrm{~s}, 65^{\circ} \mathrm{C}$ $30 \mathrm{~s}, 72^{\circ} \mathrm{C} 30 \mathrm{~s}(10$ cycles $) ; 94^{\circ} \mathrm{C} 30 \mathrm{~s}, 60^{\circ} \mathrm{C} 30 \mathrm{~s}, 72^{\circ} \mathrm{C} 30 \mathrm{~s}(30$ cycles $) ; 72^{\circ} \mathrm{C} 7 \mathrm{~min}(1 \mathrm{cycle})$. 


\subsection{Cloning of amplification products}

Reverse transcription PCR (RT-PCR) and RACE-PCR products were separated by electrophoresis, stained with ethidium bromide, excised and purified with the GFX Gel Band purification kit (Amersham) and cloned into the pGEM-T (Promega) or the pCR4-TOPO (Invitrogen) vector.

\subsection{DNA sequencing}

Sequencing was performed by MWG Biotech (Germany) and Genome express (France).

\subsection{Cloning of olive LOX cDNA for expression in E. coli}

Full-length LOX cDNA was obtained by RT-PCR using the specific primers Loxsens: 5'gagatgctgagccatatagtcgag and Loxantisens: 5'-gcttcagattgacacactgttg designed on the basis of the LOX cDNA sequence. PCR was performed with 1.25 units of $P f u$ DNA polymerase (Promega) in a $50 \mu \mathrm{L}$ reaction mix containing $1 \mu \mathrm{g}$ of cDNA template and $1 \mu \mathrm{M}$ of each primer. The amplification was performed using the following conditions: $95^{\circ} \mathrm{C} 30 \mathrm{~s}, 50^{\circ} \mathrm{C} 2$ $\min , 72^{\circ} \mathrm{C} 4 \min (1$ cycle $) ; 95^{\circ} \mathrm{C} 30 \mathrm{~s}, 55^{\circ} \mathrm{C} 2 \min , 72^{\circ} \mathrm{C} 4 \min (30$ cycles $) ; 72^{\circ} \mathrm{C} 10 \min (1$ cycle).

The PCR product was purified and cloned into the pMOS-Blue blunt ended vector (Amersham). The insert of the resulting clone, termed pMOS-LOX, was sequenced on both strands. A PCR strategy using pMOS-LOX as template was used to clone the olive LOX cDNA into the pQE-30 expression vector (Qiagen), introducing an N-terminal His tag. The

SphILoxsens: 5'-acatgcatgctgagccatatagtcgaggc and KpnILoxantisens: 5'- 
cggggtacctcagattgacacactgtt specific primers containing unique $S p h \mathrm{I}$ and $K p n I$ restriction sites were used to introduce a $S p h \mathrm{I}$ site upstream the ATG start codon and a KpnI site at the 3' end. The PCR product was cloned in the SphI-KpnI oriented direction into pQE-30 vector. The recombinant construct (pQE30-LOX) was used to transform M15 E. coli cells. Part of the plasmid was sequenced to confirm the correct frame.

\subsection{Expression and purification of the recombinant olive LOX}

Five liters of culture medium (Luria broth medium supplemented with $100 \mu \mathrm{g} \cdot \mathrm{mL}^{-1}$ ampicillin and $25 \mu \mathrm{g} . \mathrm{mL}^{-1}$ kanamycin) were inoculated with the overnight culture of the M15 E. coli transformed with $\mathrm{pQE} 30-\mathrm{LOX}$ and incubated at $37^{\circ} \mathrm{C}$ until the cell density had increased to $\mathrm{A}_{600}$ 0.6. Then IPTG ( $1 \mathrm{mM}$ final concentration) was added and the culture incubated at $15^{\circ} \mathrm{C}$ for a further $24 \mathrm{~h}$. The culture was centrifuged $20 \mathrm{~min}$ at $7000 \mathrm{x} \mathrm{g}$, the pellet resuspended in $250 \mathrm{~mL}$ of lysis buffer $\left(50 \mathrm{mM}\right.$ sodium phosphate buffer $\mathrm{pH} 8$ containing $0.25 \mathrm{mg} \cdot \mathrm{mL}^{-1}$ lysozyme, $1 \mathrm{mM}$ benzamidine, $5 \mathrm{mM} \mathrm{MgCl} 2,0.01 \mathrm{mg} \cdot \mathrm{mL}^{-1}$ of DNase I, $500 \mathrm{mM} \mathrm{NaCl}$ and $0.1 \%$ Triton $\mathrm{X}-100)$ and the cell lysis was performed by freezing and thawing twice. After centrifugation at $25,000 \mathrm{x}$ g for $15 \mathrm{~min}$, the supernatant (soluble protein fraction) was loaded onto Ni-NTA (Qiagen) column (2 mL bed volume) pre-equilibrated with buffer A (50 mM sodium phosphate buffer $\mathrm{pH} 8$ containing $500 \mathrm{mM} \mathrm{NaCl}$ ). Most of the $E$. coli proteins elute in the flow through, and once the $\mathrm{A}_{280}$ of the effluent returned to baseline, the bound proteins were eluted with a linear imidazole gradient of 5-250 $\mathrm{mM}$ in buffer A. Fractions enriched in LOX activity were pooled, concentrated and subjected to gel filtration on a Hiload 26/60 Superdex 200 (Amersham Biosciences) prep grade pre-equilibrated with $50 \mathrm{mM}$ sodium phosphate buffer pH 6 containing $500 \mathrm{mM} \mathrm{NaCl}$. Fractions showing LOX activity and containing pure protein on SDS-PAGE were pooled and concentrated by using an Amicon 
Ultra-15 membrane with a molecular weight cutoff of 30,000 (Millipore). The concentrated protein sample $\left(11.7 \mathrm{~mL}\right.$ at $\left.0.358 \mathrm{mg} \cdot \mathrm{mL}^{-1}\right)$ was stored at $-80^{\circ} \mathrm{C}$ until used.

\subsection{Determination of protein concentration}

Protein concentration was determined spectroscopically for the pure recombinant olive LOX using an $\mathrm{A}_{280}$ extinction coefficient $(\varepsilon)$ of $144,090 \mathrm{M}^{-1} \cdot \mathrm{cm}^{-1}$ that was calculated from the tyrosine and tryptophan content $[20,21]$ of the deduced amino acid sequence. Protein concentration in other samples was determined by the Bradford method using bovine serum albumine as standard [22].

\subsection{SDS-polyacrylamide gel electrophoresis (SDS-PAGE) and immunoblotting}

SDS-PAGE was performed using $12 \%$ polyacrylamide gels. The proteins were stained with Coomassie brilliant blue R-250 or transferred onto nitrocellulose (Bio-rad). Blots were blocked overnight using 3\% BSA and were probed with the monoclonal peroxidaseconjugated anti-His antibody (Sigma) at 1:4,000. The peroxidase was revealed using $1.3 \mathrm{mM}$ 3,3'-diaminobenzidine tetrahydrochloride (DAB) (Sigma) in PBS (phosphate buffer pH 7.3,

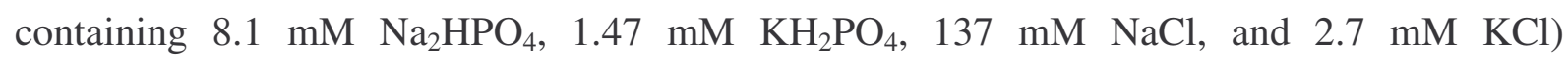
containing $0.01 \% \mathrm{H}_{2} \mathrm{O}_{2}$.

\subsection{Preparation of LOX crude extracts}

The frozen pulp of the olives was blended into a fine powder. One gram of frozen pulp powder was resuspended in 10 times their mass of $50 \mathrm{mM}$ phosphate buffer at $\mathrm{pH} 6$ 
containing $1 \mathrm{mM}$ phenylmethylsulfonyl fluoride (PMSF) by homogenization during 2 minutes at 8,000 rpm with an Ultra-Turrax T25 (IKA. Labortechnik). The resulting homogenate was then filtered onto 4 layers of cheeseclothes and centrifuged for $10 \mathrm{~min}$ at $200 \mathrm{x} \mathrm{g}$. The resulting supernatant was subsequently assayed for lipoxygenase activity.

\subsection{LOX activity and substrate specificity}

LOX activity was determined by continuously monitoring the formation of conjugated dienes at $235 \mathrm{~nm}$ [23]. The linoleic acid substrate was prepared as described by Anthon and Barret [24]. Enzymatic assays were performed at saturating oxygen concentration. The standard assay mixture consisted in $1 \mathrm{~mL}$ of $50 \mathrm{mM}$ phosphate buffer $(\mathrm{pH} \mathrm{6.0)}$ and the appropriate amount of enzyme extract $(5-10 \mu \mathrm{L})$. Reactions were started by the addition of $0.25 \mathrm{mM}$ of linoleic acid. One unit of LOX activity is defined as the amount of enzyme catalysing the formation of $1 \mu \mathrm{mol}$ of hydroperoxide per minute at $25^{\circ} \mathrm{C}$.

The kinetic parameters have been determined from a Michaelis-Menten plot over a range of substrate concentrations (linoleic and linolenic acids) between 75 and $375 \mu \mathrm{M}$.

Propyl gallate $(0-6.6 \mu \mathrm{M})$ and nordihydroguaiaretic acid (NDGA) $(0-33 \mu \mathrm{M})$ were used for the inhibition experiments.

\subsection{Synthesis and analysis of LOX products}

Hydroperoxide of linoleic acid was synthesized according to Vick and Zimmerman [25] with adaptations. Purified recombinant olive LOX (90 Units), $5.36 \mathrm{mM}$ of linoleic acid, and 11 $\mathrm{mM} \mathrm{NaOH}$ were added to $50 \mathrm{mM}$ sodium phosphate buffer ( $\mathrm{pH} 6.0$ ) containing $3 \mathrm{mM}$ of $\mathrm{CaCl}_{2}$, previously oxygenated at $4^{\circ} \mathrm{C}$. After $30 \mathrm{~min}$, under gentle oxygenation, the reaction 
was stopped by acidification. Hydroperoxides were extracted with 3 x $30 \mathrm{~mL}$ of diethyl ether and washed with 2 x $30 \mathrm{~mL}$ of water. Solvent was removed and replaced by $\mathrm{CDCl}_{3}$ for $\mathrm{NMR}$ experimentation. The yield of hydroperoxide evaluated by ${ }^{13} \mathrm{C}-\mathrm{NMR}$ was $25 \%$.

Identification of LOX products was performed as described by Lorenzi et al. [13] using a Bruker 400 Avance Fourier Transform spectrometer operating at a $100.623 \mathrm{MHz}$ for ${ }^{13} \mathrm{C}$, equipped with a $5 \mathrm{~mm}$ probe, in deuteriochloroform, with all shifts referred to internal tetramethylsilane (TMS). ${ }^{13} \mathrm{C}-\mathrm{NMR}$ spectra were obtained with the following acquisition parameters : pulse width $45^{\circ}(4 \mu \mathrm{s})$, acquisition time $2.73 \mathrm{~s}$ for $128 \mathrm{~K}$ data table with a spectral width of $25000 \mathrm{~Hz}(250 \mathrm{ppm})$, digital resolution $=0.183 \mathrm{~Hz}$ per point. ${ }^{13} \mathrm{C}-\mathrm{NMR}$ chemical shift of hydroperoxides extracted was compared to values obtained by Lorenzi et al. [13] with soybean commercial LOX on esterified 9- and 13- hydroperoxides of linoleic acid:

${ }^{13} \mathrm{C}-\mathrm{NMR}\left(100 \mathrm{MHz}, \mathrm{CDCl}_{3}\right) \delta 134.03$ (9-OOH, C-12), 133.86 (13-OOH, C-11), 131.31 (13-OOH,C-11), 131.14 (9-OOH, C-11), 130.00 (9-OOH, C-10), 129.91 (13-OOH, C12), 127.56 (13-OOH, C-9), 127,38 (9-OOH, C-13), 86.82 (13-OOH, C-13), 86.72 (9-OOH, C-9) 31.75 (13-OOH, C-16), 31.51 (9-OOH, C-16), 27.92 (9-OOH, C-14), 27.70 (13-OOH, C-8), 25.21 (9-OOH, C-7), 24.97 (13-OOH, C15).

Enantiomer composition analysis was carried out by chiral-phase HPLC with on-line MS/MS [26]. The hydroperoxides were reduced by triphenylphosphine, separated by chiral phaseHPLC on a column with amylose tris(3,5-dimethylphenylcarbonate) coated on silica gel (Reprosil Chiral-AM; $10 \mu \mathrm{m} ; 250 \mathrm{~mm} \mathrm{x} 2 \mathrm{~mm}$; Dr. Maisch) and eluted with ethanol/hexan/acetic acid, 95/5/0.02 $\left(0.15 \mathrm{~mL} \cdot \mathrm{min}^{-1}\right)$. The effluent was mixed in a tee with isopropanol/water, $3 / 2$ at $0.1 \mathrm{~mL} \cdot \mathrm{min}^{-1}$ and the products were detected by MS/MS analysis of carboxylate anions. The capillary temperature was $315^{\circ} \mathrm{C}$, the spray voltage was $4.5 \mathrm{kV}$, and prostaglandin $\mathrm{F}_{1 \alpha}$ was utilized for tuning. Mass spectrometry experiments were performed on 
a linear ion-trap (LIT) mass spectrometer using Xcalibur as operating system (LTQ, ThermoFisher). Electrospray ionization was conducted and negative ions were detected.

\section{Results}

\subsection{LOX cDNA isolation and characterization}

We isolated a full length cDNA by a combined strategy using RT-PCR and RACEPCR on total RNA extracted from black olives harvested at 30 weeks after flowering (WAF) and oligonucleotides designed on the basis of the sequence of known plant LOXs and during this study (Fig. 1). The olive LOX cDNA (GenBank accession number: EU678670) harboured an open reading frame (ORF) of 2592 bp encoding a presumptive translation product of 864 amino acid residues. The product with a calculated molecular mass of 98.4 $\mathrm{kDa}$ and a $\mathrm{pI}$ of 5.95 is likely confined to the cytosol, because it contained neither consensus targeting nor retention signals for any organelles (pSORT programm; http://psort.ims.utokyo.ac.jp). The ORF is flanked by a 5'-unstranslated (UTR) sequence that is at least 99nucleotides (nt) and a 157-nt 3'-UTR containing a canonical polyadenylation signal (Fig. 1). The alignment of the deduced amino acid sequence with other LOX sequences using ClustalW program shows that the olive LOX contained the two functional domains typical of LOXs: the smaller $\mathrm{N}$-terminal region (position 1-164) forming a $\beta$-barrel structure, known to mediate binding of lipid body LOX to liposomes and lipid bodies [27], and the larger Cterminal region (position 165-864) including the catalytic site [28]. 
FASTA analysis of the deduced amino acid sequence revealed that olive LOX shared the highest degree of identity towards hazelnut LOX (77.3\% identity, [29]) tobacco LOX1 (76.3\% identity, [30]) and almond LOX (75.5\% identity, [31]).

Several highly conserved regions were identified: the domains likely to be important for the substrate binding (position 364-378) and the oxygen binding (position 710-723), the C-terminal GIPNSVSI domain, as well as the residues (H525, H530, H716, N720 and I864) involved in the iron binding (Fig. 1).

The regio-specificity in plant LOXs are usually determined by the motif $\mathrm{R} / \mathrm{TF}, \mathrm{R} / \mathrm{TH}$, R/CF or R/SF for 13-LOX and R/TV for 9-LOX [5]. Olive LOX contained a threonine-valine motif (R/TV at positions 733/582-583; Fig. 1) suggesting that this enzyme is a 9-LOX.

\subsection{Genomic polymorphism of the Lox gene}

To determine the number of the olive Lox genes, we carried out Southern blot analysis using the two LOX cDNA probes. We perform an alignment of olive LOX cDNA nucleic sequence using the ClustalW program with the genomic Lox sequence of Solanum tuberosum (accession number U24232). We predicted that the LOX probe1 spans the exon 2 to exon 4 and contains one EcoRI site in the exon 2 and 4, and one BamHI site in the exon 3 (Fig. 2A). The LOX probe2 which could be included in the exon 9 contains one EcoRI site (Fig. 2A). The LOX probe1 and LOX probe 2 contain no XhoI site, and a unique XhoI site present in the olive LOX cDNA is located just in 5' of the LOX probe2.

The resulting pattern of hybridization with the LOX probe2 (Fig. 2B) consisted of a single band, at $0.7 \mathrm{~kb}$ and $6.1 \mathrm{~kb}$ in length, with the EcoRI and BamHI digestions, respectively, and two bands, at $9.3 \mathrm{~kb}$ and $7.5 \mathrm{~kb}$ in length, with the XhoI digestion. These results suggest the presence of one Lox gene copy with a XhoI polymorphism. The 
hybridization pattern obtained with the LOX probe 1 showed two bands, at $1.3 \mathrm{~kb}$ and $0.75 \mathrm{~kb}$ in length, with the EcoRI digestion, two bands, at $12.6 \mathrm{~kb}$ and $6.1 \mathrm{~kb}$ in length, with the Bam HI digestion, and three bands at $16.9 \mathrm{~kb}, 11.3 \mathrm{~kb}$ and $8.9 \mathrm{~kb}$ in length, with the XhoI digestion. The number of DNA fragments detected for the EcoRI and BamHI digestions is in agreement with a single copy of our Lox gene. Altogether these results showed an XhoI polymorphism for this gene.

\subsection{Biochemical characterization of recombinant olive LOX}

Expression of the olive LOX was induced by $1 \mathrm{mM}$ IPTG and low temperature $\left(15^{\circ} \mathrm{C}\right)$ incubation to prevent inclusion body formation. Protein extracts of E. coli harbouring the pQE30-LOX vector showed a specific LOX activity (0.9 U. $\mathrm{mg}^{-1}$ protein) with linoleic acid as substrate, and no LOX activity using the empty vector. These results indicate that olive LOX cDNA encoded a functional enzyme. The recombinant enzyme was purified by affinity chromatography using Nickel chelated column followed by Superdex 200 gel filtration chromatography. The specific activity reached $23.4 \mathrm{U}_{\mathrm{mg}}{ }^{-1}$ protein with linoleic acid as substrate and a 26-fold purification was achevied. We have obtained $4.18 \mathrm{mg}$ of recombinant protein from five liters of culture medium. Purified recombinant olive LOX appeared as a unique band at $98 \mathrm{kDa}$ in both Coomassie brilliant blue stained SDS-PAGE and immunoblot, in good agreement with the predicted molecular mass (Fig. 3).

The enzymatic activity was analyzed at different $\mathrm{pH}$ values $(\mathrm{pH} 4-9)$ and we found that recombinant olive LOX has an optimum $\mathrm{pH}$ of about 6 . The kinetics parameters were investigated using linoleic and linolenic acids as substrates (Table 1). The recombinant olive LOX showed a lower $\mathrm{K}_{\mathrm{m}}$ for linoleic acid $(174.94 \mu \mathrm{M})$ than for linolenic acid (343.66 $\left.\mu \mathrm{M}\right)$. The estimates of $\mathrm{k}_{\mathrm{cat}} / \mathrm{K}_{\mathrm{m}}$ for linoleic acid hydroperoxidation $\left(0.28 \mathrm{~s}^{-1} \cdot \mu \mathrm{M}^{-1}\right)$ and for linolenic 
acid hydroperoxidation $\left(0.14 \mathrm{~s}^{-1} \cdot \mu \mathrm{M}^{-1}\right)$ suggested that the catalytic efficiency of the recombinant olive LOX was significantly higher for linoleic acid hydroperoxidation than for linolenic acid hydroperoxidation. Inhibition studies were performed with LOX inhibitors such as propyl gallate and NDGA [32]. The inhibition kinetics analysed by Lineweaver-Burk plots showed that propyl gallate was a competitive inhibitor, and a $\mathrm{K}_{\mathrm{i}}$ value of $1.88 \mu \mathrm{M}$ was graphically determined using secondary plots. NDGA inhibition was non competitive with a $\mathrm{K}_{\mathrm{i}}$ value of $4.09 \mu \mathrm{M}$.

In order to determine the regio-specificity of the recombinant olive LOX, we analyzed by ${ }^{13} \mathrm{C}$-NMR the reaction products obtained using linoleic acid as substrate. We clearly observed that 9-hydroperoxy octadecadienoic acid (9-HPODE) (characteristic signals, $\delta, \mathrm{ppm}$ : $134.26,131.02,130.16,127.38,86.81,31.45,27.82,25.20)$ was formed rather than 13hydroperoxy octadecadienoic acid (13-HPODE) (characteristic signals, $\delta$, ppm: 133.96, $131.21,130.07,127.56,86.86,31.74,27.67,24.97$ ) with a ratio about 2:1 (Fig. 4).

The stereo chemistry of 9- and 13-HPODE was analyzed by chiral-phase HPLC after reduction to the corresponding alcohols. 9-HPODE and 13-HPODE were formed in a 2:1 ratio (data not shown) and were predominantly in the 9S and 13R configuration (Fig. 5), indicating that they derived from the activity of a specific enzyme.

\subsection{LOX expression and enzymatic activity during olive fruit development}

We identified the developmental stages on the basis of the olive colour: green stage (harvested from 8 to $16 \mathrm{WAF}$ ), turning stage (harvested at $18 \mathrm{WAF}$ ) and black stage (harvested from 20 to $32 \mathrm{WAF}$ ). The enzymatic activity was preliminarily analyzed at different $\mathrm{pH}$ values ( $\mathrm{pH} 4-9$ ) on the olives harvested every two weeks and we found that the olive LOX activity has an optimum $\mathrm{pH}$ of about 6 whatever the stage of development. LOX 
activity was detected in all olive developmental and ripening stages from green small fruits (8 WAF) to black or senescent fruits (32 WAF, Fig. 6A). An increase of the LOX activity was observed at the end of the green stage and the turning stage of the olives, and the maximum (783 nmol. $\mathrm{min}^{-1} \cdot \mathrm{mg}^{-1}$ of proteins) was reached at the black stage.

LOX expression was monitored by Northern analysis using the LOX probe1. An hybridization signal of the expected size for LOX RNA (2.9 kb) was observed in olives harvested from $22 \mathrm{WAF}$ to $32 \mathrm{WAF}$, with a strong signal for the olives at $32 \mathrm{WAF}$ (Fig. 6B). A faint signal was observed in olive at 24 WAF which can be explained by a smaller quantity of RNA loaded (Fig. 6B, 6C). No hybridization was observed in olives of the green stage, of the turning stage or in the first sample of the black stage (20 WAF). A similar hybridization pattern was observed with the LOX probe2 (data not shown).

\section{Discussion}

Using a RT-PCR and RACE-PCR combined approach on total RNA isolated from black olives harvested at $30 \mathrm{WAF}$, we have isolated and characterized, for the first time, an olive cDNA encoding a LOX isoform. We have shown that this olive LOX is probably encoded by a unique copy of the gene. Amino acid sequence analysis of this olive LOX has shown that the polypeptide contains all of the domains and amino acid residues known to be important for LOX activity. A classification of plant LOXs based on the presence of the chloroplastic transit peptide was introduced by Shibata et al. [33]. The members of the socalled type-2 LOX exhibit this N-terminal extension in contrast to those reassembled in the type-1 LOX subfamily. Our olive LOX isoform, which is likely a cytoplasmic isoform, can be classified among the type-1 LOXs. Plant LOXs are also classified into 9- and 13-LOXs with respect to the position at which the oxygenation of linoleic acid occurs. The primary determinant for regio-specificity was defined by the R/TF, R/TH, R/SF or R/CF motif for 13- 
LOX and by the R/TV motif for the 9-LOX [5]. A special role of an Arg residue at the bottom of the substrate-binding pocket was suggested by its highly conserved occurrence in all plant LOXs and by mutagenesis studies [34,35]. In plant 13-LOXs, the His or Phe residue would mask the positive charge of the Arg and would hamper the interaction with the linoleate carboxylate. Thus, the linoleate would penetrate in the active site by its methyl end, and the C-13 oxidation would occur. In contrast, for the plant 9-LOXs, the replacement of the His or Phe residue by the less space-filling Val residue would allow an inverse orientation of the linoleate in the active site what would favour the C-9 oxidation [5]. However, some plant LOXs produce both 9- and 13-hydroperoxide isomers, and thus do not follow the predictive model of regio-specificity $[36,37]$. According to the R/TV motif found in the recombinant olive LOX, the 9-LOX activity would be predicted. Surprisingly, as shown by ${ }^{13} \mathrm{C}-\mathrm{NMR}$ and HPLC-MS analysis, both 9- and 13-hydroperoxide of linoleic acid, predominantly in the 9S and $13 R$ configuration, were produced in a 2:1 ratio by the recombinant olive LOX. Thus, this enzyme displayed a dual positional specificity and would be defined as olive 9/13-LOX. The LOX specificity has implications for hydroperoxides metabolism. Indeed, 9- and 13hydroperoxides of linoleic and linolenic acids can be converted into volatile aldehydes by hydroperoxide lyase(s), whereas 13-hydroperoxide of linolenic acid can be converted into jasmonic acid cyclic precursors by allene oxide synthase. The dual positional specificity of the 9/13-LOX suggests that it is able to synthesize compounds that play roles in both developmental process and defence response [6].

During the development of olives, the LOX activity shows an increase at the end of the green stage and the turning stage to reach a maximum at black stage. Donaire et al. [11] and Salas et al. [12] have previously reported a LOX activity at early stages of the olive development. Here, we report that although the LOX activity is detected at early stages of the olive development, this activity is lower than the activity observed in olives of the black stage. 
These results are not surprising since LOXs are associated with plant senescence and fruit ripening. Indeed, LOXs have long been associated with membrane deterioration in plant tissues through peroxidation of PUFAs, and such dysfunction has been seen as a key process in senescence, resulting in loss of compartmentation and cell breakdown [38,39]. Moreover LOX activity has been shown to increase in conjunction with ripening processes such as loss firmness in kiwifruit [40,41] and peach fruit [42].

As shown by the Northern analysis, the 9/13-LOX is specifically expressed in olives of the black stage from the $22 \mathrm{WAF}$ to the $32 \mathrm{WAF}$. Another LOX enzyme was recently purified from black olives and characterized as a 13-LOX [13] indicating that at least two LOX differing in their regio-specificity are expressed in olives of the black stage. Both, 9/13LOX and 13-LOX showed a preference towards linoleic acid (with a $\mathrm{K}_{\mathrm{m}}=174.94 \mu \mathrm{M}$ and 82.44 $\mu \mathrm{M}$ respectively) than linolenic acid (with a $\mathrm{K}_{\mathrm{m}}=343.66 \mu \mathrm{M}$ and $306.26 \mu \mathrm{M}$ respectively), and the $\mathrm{K}_{\mathrm{m}}$ values suggested that the fatty acid pocket of 13-LOX had a significantly higher affinity for linoleic acid than 9/13-LOX. However, the catalytic efficiency of 9/13-LOX for linoleate hydroperoxidation was higher than that of 13-LOX. Luaces et al. [14] reported recently two LOX isoforms (a thermo-labile and a thermo-resistant isoforms) from green olives of the early developmental stage which might be involved in the biosynthesis of the olive oil aroma. Our 13-LOX [13] and the thermo-resistant LOX could correspond to only one and even isoform since they displayed an activation energy in the

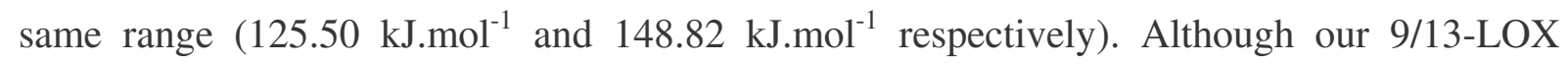
displays an activation energy of $82.37 \mathrm{~kJ} \cdot \mathrm{mol}^{-1}$, which is close to that of the thermo-labile LOX (83.39 kJ.mol ${ }^{-1}$ ) reported by Luaces et al. [14], they correspond to two Lox genes since our 9/13-LOX is not expressed in green olives. The expression of different LOXs during their development could explain the LOX activity detected throughout the development process. Multiple isoforms of LOX have been found in a wide range of plants [5]. In tomato, for 
example, at least five Lox genes have been reported: TomloxA expression declines during tomato fruit ripening, and TomloxB expression is present in mature green fruit and enhanced by ethylene [43]; TomloxC is detectable in the onset of ripening and has been identified as a specific isoform involved in synthesis of fruit flavour compounds [44]; TomloxD shows low expression levels in fruit, but is rapidly and transiently induced by wounding [45], and TomloxE transcripts are present at the breaker and post-breaker stages of fruit ripening [44]. More recently, six Lox genes were identified and cloned from a kiwifruit EST (expressed sequence tag) database [46]. The results showed that the six genes were differentially regulated during kiwifruit ripening and senescence, forming two groups, one active in ripening and responsive to ethylene and the other more constitutively expressed. To date, the physiological role of the olive 9/13-LOX is still unknown, but its expression pattern suggests that it is associated with the ripening and senescence processes. Moreover, as it is expressed in olives of black stage, its contribution to the biosynthesis of the olive oil aroma cannot be ruled out.

The identification of LOX, expressed in the fruit and more widely in the plant, with tissue-specific regulation during development or in response to abiotic and biotics elicitors of stress, and their characterization as recombinant proteins, should prove to be a useful approach to interpret the role of LOXs in plant biology, and in olive in particular in the elaboration of the olive oil aroma.

\section{Acknowledgments}

This work has been supported by the "Collectivité Territoriale de Corse", Interreg IIIA and Knut and Alice Wallenberg Foundation (KAW 2004.0123). The authors thank Delphine Fontaine (U837-Lille) for her technical help. 
Abbreviations: LOX, lipoxygenase; PUFA, polyunsaturated fatty acid 


\section{References}

[1] A.N. Grechkin, Recent developments in biochemistry of the plant lipoxygenase pathway, Prog. Lipid Res. 37 (1998) 317-352.

[2] J. Vidal-Mas, M. Busquets, A. Manresa, Cloning and expression of a lipoxygenase from Pseudomonas aeruginosa 42A2, Antonie van Leeuwenhoek. 87 (2005) 245-251.

[3] T. Koeduka, T. Kajiwara, K. Matsui, Cloning and lipoxygenase genes from a cyanobacterium, Nostoc punctiforme, and its expression in Escherichia coli, Curr. Microbiol. 54 (2007) 315-319.

[4] H. Porta, M. Rocha-Sosa, Plant lipoxygenase. Physiological and molecular features, Plant Physiol. 130 (2002) 15-21.

[5] I. Feussner, C. Wasternack, The Lipoxygenase pathway, Annu. Rev. Plant Biol. 3 (2002) 275-297.

[6] J.N. Siedow, Plant lipoxygenase: structure and function, Annu. Rev. Plant Physiol. Plant Mol. Biol. 42 (1991) 145-188.

[7] E. Blée, Phytooxylipins and plant defence reactions, Prog Lipid Res. 37 (1998) 33-72.

[8] D.S. Robinson, Z. Wu, Z. Domoney, R. Casey, Lipoxygenases and the quality of foods, Food Chem. 54 (1995) 33-43.

[9] F. Angerosa, C. Basti, R. Vito, Virgin olive oil volatile compounds from lipoxygenase pathway and characterization of some Italian cultivars, J. Agric. Food Chem. 47 (1999) 836-839.

[10] W. Dhifi, F. Angerosa, A. Serraiocco, I. Oumar, I. Hamrouni, B. Marzouk, Virgin olie oil aroma: characterization of some Tunisian cultivars, Food Chem. 93 (2005) 697-701. 
[11] J.P. Donaire, A. Belver, M.I. Rodriguez-Garcia, L. Megias, Lipid biosynthesis, oxydative enzyme activities and cellular changes in growing olive fruits, Rev. Esp. Fisiol. 40 (1984) 191-204.

[12] J.J. Salas, M. Williams, J.L. Harwood, J. Sanchez, Lipoxygenase activity in olive (Olea europaea) fruit, J. Am. Oil Chem. Soc. 76 (1999) 1163-1167.

[13] V. Lorenzi, J. Maury, J. Casanova, L. Berti, Purification, product characterization and kinetic properties of lipoxygenase from olive fruit (Olea europaea L.), Plant Physiol. Biochem. 44 (2006) 450-454.

[14] P. Luaces, C. Sane, A.G. Pérez, Thermal stability of lipoxygenase and hydroperoxide lyase from olive fruit and repercussion on olive oil aroma biosynthesis, J. Agric. Food Chem. 55 (2007) 6309-6313.

[15] J.M. Olias, A.G. Pérez, J.J. Rios, C. Sanz, Aroma of virgin olive oil: biogenesis of the green odor notes, J. Agric. Food Chem. 41 (1993) 2368-2373.

[16] M.L. Hernández, M. Mancha, J.M. Martínez-Rivas, Molecular cloning and characterization of genes encoding two microsomal oleate desaturases (FAD2) from olive, Phytochemistry 66 (2005) 1417-1426.

[17] J. Sambrook, E.F. Fritsch, T Maniatis, Molecular cloning. A laboratory manual, 2nd Edition. Cold Spring Harbor Laboratory Press, Cold Spring Harbor, New York, 1989.

[18] M.A. Saghai-Maroof, K.M. Soliman, R.A. Jorgensen, R.W. Allard, Ribosomal DNA spacer-length polymorphisms in barley: mendelian inheritance, chromosomal location, and population dynamics, Proc. Natl. Acad. Sci. U.S.A. 81 (1984) 8014-8018.

[19] V. Bronzini De Caraffa, J. Maury, C. Gambotti, C. Breton, A. Bervillé, J. Giannettini, Mitochondrial DNA variation and RAPD mark oleasters, olive and feral olive from Western and Eastern Mediterranean, Theor. Appl. Genet. 104 (2002) 1209-1216. 
[20] H. Edelhoch, Spectroscopic determination of tryptophan and tyrosine in proteins, Biochemistry 6 (1967) 1948-1954.

[21] S.C. Gill, P.H. Von Hippel, Calculation of protein extinction coefficients from amino acid sequence data, Anal. Biochem. 182 (1989) 319-326.

[22] M.M. Bradford, A rapid and sensitive for the quantitation of microgram quantitites of protein utilizing the principle of protein-dye binding, Anal. Biochem. 72 (1976) 248254.

[23] B. Axelrod, T.M. Cheesbrough, S. Laakso, Lipoxygenase from soybeans: EC 1.13.11.12 Linoleate:oxygen oxidoreductase, Meth. Enzymol. 71 (1981) 441-445.

[24] G.E. Anthon, D.M. Barrett, Thermal inactivation of lipoxygenase and hydroperoxytrienoic acid lyase in tomatoes, Food Chem. 81 (2003) 275-279.

[25] B.A. Vick, D.C. Zimmerman, Pathways of fatty acid hydroperoxide metabolism in spinach leaf chloroplasts, Plant Physiol. 85 (1987) 1073-1078.

[26] C. Schneider, Z. Yu, W.E. Boeglin, Y. Zheng, A.R. Brash, Enantiomeric separation of hydroxy and hydroperoxy eicosanoids by chiral column chromatography, Meth. Enzymol. 433 (2007) 145-157.

[27] C. May, M. Höhne, P. Gnau, K. Schwennesen, H. Kindl, The N-terminal beta-barrel structure of lipid body lipoxygenase mediates its binding to liposomes and lipid bodies, Eur. J. Biochem. 267 (2000) 1100-1109.

[28] J.C. Boyington, B.J. Gaffney, L.M. Amzel, Structure of soybean lipoxygenase-I, Biochem. Soc. Trans. 21 (1993) 744-748.

[29] A. Santino, A. De Paolis, A. Gallo, A. Quarta, R. Casey, G. Mita, Biochemical and molecular characterization of hazelnut (Corylus avellana) seed lipoxygenases, Eur. J. Biochem. 270 (2003) 4365-4375. 
[30] C. Veronesi, J. Fournier, M. Rickauer, M. Marolda, M.T. Esquerre-Tugaye, Nucleotide sequence of an elicitor-induced tobacco lipoxygenase cDNA (PGR95-009), Plant Physiol. 108 (1995) 1342-1342.

[31] G. Mita, A. Gallo, V. Greco, C. Zasiura, R. Casey, G. Zacheo, A. Santino, Molecular cloning and biochemical characterization of a lipoxygenase in almond (Prunus dulcis) seed, Eur. J. Biochem. 268 (2001) 1500-1507.

[32] S. Fornaroli, E. Petrussa, E. Braidot, A. Vianello, F. Macri, Purification of a plasma membrane-bound lipoxygenase from soybean cotyledons, Plant Sci. 145 (1999) 1-10.

[33] D. Shibata, A. Slusarenko, R. Casey, D. Hildebrand, E. Bell, Lipoxygenases, Plant Mol. Biol. Report. 12 (1994) S41-S42.

[34] A. Liavonchanka, I. Feussner, Lipoxygenases: Occurrence, functions and catalysis, J. Plant Physiol. 163 (2006) 348-357.

[35] E. Hornung, M. Walther, H. Kuhn, I. Feussner, Conversion of cucumber linoleate 13lipoxygenase to a 9-lipoxygenating species by site-directed mutagenesis, Proc. Natl. Acad. Sci. U.S.A. 96 (1999) 4192-4197.

[36] R.K. Hughes, S.I. West, A.R. Hornostaj, D.M. Lawson, S.A. Fairhurst, R.O. Sanchez, P. Hough, B.H. Robinson, R. Casey, Probing a novel potato lipoxygenase with dual positional specificity reveals primary determinants of substrate binding and requirement for a surface hydrophobic loop and has implications for the role of lipoxygenases in the tuber, Biochem. J. 353 (2001) 345-355.

[37] R.K. Hughes, D.M. Lawson, A.R. Hornostaj, S.A. Fairhurst, R. Casey, Mutagenesis and modelling of linoleate-bonding to pea seed lipoxygenase, Eur. J. Biochem. 268 (2001) 1030-1040. 
[38] J.E. Thompson, The molecular basis for membrane deterioration during senescence, in: L.D. Nooden, A.C. Leopold (Eds), Senescence and aging in plants, Academic Press, New York, 1988, pp51-83

[39] S.Y. Rogiers, G.N.M. Kumar, N.R. Knowles, Maturation and ripening of fruit of Amelanchier alnifolia Nutt. are accompanied by increasing oxidative stress, Ann Bot (Lond). 81 (1998) 203-211.

[40] K.S. Chen, C.J. Xu, J. Lou, S.L. Zhang, GS. Ross, Lipoxygenase in relation to the ripening and softening of Actinidia fruit, Acta Phytophysiol. Sin. 25 (1999) 138-144.

[41] Y. Zhang, K.S. Chen, S.L. Zhang, I. Ferguson, The role of salicylic acid in postharvest ripening of kiwifruit, Postharvest Biol. Tech. 28 (2003) 67-74.

[42] M. Wu, K.S. Chen, S.L. Zhang, Involvement of lipoxygenase in the postharvest ripening of peach fruit, Acta Hortic. Sin. 26 (1999) 227-231.

[43] A. Griffiths, C. Barry, A.G. Alpuche-Solis, D. Grierson, Ethylene and developmental signals regulate expression of lipoxygenase genes during tomato fruit ripening, J. Exp. Bot. 50 (1999) 793-798.

[44] G.P. Chen, R. Hackett, D. Walker, A. Taylor, Z.F. Lin, D. Grierson, Identification of a specific isoform of tomato lipoxygenase (TomloxC) involved in the generation of fatty acid-derived flavor compounds, Plant Physiol. 136 (2004) 2641-2651.

[45] T. Heitz, D.R. Bergey, C.A. Ryan, A gene encoding a chloroplast-targeted lipoxygenase in tomato leaves is transiently induced by wounding, systemin, and methyl jasmonate, Plant Physiol. 114 (1997) 1085-1093.

[46] B. Zhang, K. Chen, J. Bowen, A. Allan, R. Espley, S. Karunairetnam, I. Ferguson, Differential expression within the LOX gene family in ripening kiwifruit, J. Exp. Bot. 57 (2006) 3825-3836. 


\section{LEGEND TO FIGURES}

Fig. 1. Compiled full-length olive LOX cDNA sequence and deduced amino acid sequence. Nucleotide and amino acid positions are indicated by the numbers at the right. The cDNA fragments obtained by RT-PCR, RACE-PCR or PCR are indicated by arrows. The proposed substrate binding domains (positions 364-378 and 710-723) and the conserved C-terminal domain are double underlined. Presumed specific amino acid residues responsible for regiospecificity are boxed. The amino acid residues related to binding iron atom are encircled. The putative polyadenylation signal (AATAAA) is underlined.

Fig. 2. Southern hybridization of olive leaves genomic DNA of Leccino variety with LOXprobe1 and LOXprobe2. (A) Schematic representation of the predicted genomic organization of the olive Lox gene deducted from the nucleic sequence alignment of the olive LOX cDNA with the Solanum tuberosum Lox gene (accession number U24232). The translation start and stop codons are indicated. Boxes represent the exons (sizes are indicated, the 5'-UTR and 3'-UTR are shaded), and the single line between boxes represents the introns. E, B and X indicate the position of restriction sites for EcoRI, BamHI and XhoI, respectively. (B) Genomic DNA $(10 \mu \mathrm{g})$ was digested with EcoRI (E), BamHI (B) and XhoI (X) and hybridized with the two LOX cDNA probes. DNA size standards in kb are shown on the left.

Fig. 3. SDS-PAGE (12\% acrylamide) of olive LOX at various steps of the purification. The proteins were stained with Coomassie brilliant blue R-250 staining (lane M, 1, 2 and 3), or revealed by immunoblotting technique using the specific monoclonal peroxidase conjugated anti-His antibody (lane 4). Lane M, molecular mass standards. Lane 1, soluble extract (25 $\mu \mathrm{g})$ of cell lysate following centrifugation. Lane 2, Ni-NTA pooled fractions containing olive 
LOX $(25 \mu \mathrm{g})$. Lane 3, Superdex 200 pooled fractions containing olive LOX (10 $\mu \mathrm{g})$. Lane 4, immunoblot of Superdex 200 pooled fractions $(3 \mu \mathrm{g})$.

Fig. 4. Expanded plot of ${ }^{13} \mathrm{C}-\mathrm{NMR}$ spectrum of products obtained by incubating linoleic acid with recombinant olive LOX. Peak 1: carbon 13 of 13-hydroperoxy octadecadienoic acid, peak 2: carbon 9 of 9-hydroperoxy octadecadienoic acid.

Fig. 5 Chiral-phase HPLC-MS/MS analysis of metabolites formed from linoleic acid by recombinant olive LOX. Top trace, separation of the enantiomers of 9-hydroxy octadecadienoic acid and MS/MS analysis ( $m / z, 295 \rightarrow$ full scan ) with monitoring $m / z 171$. Bottom trace, separation of the enantiomers of 13- hydroxy octadecadienoic acid and MS/MS analysis $(m / z, 295 \rightarrow$ full scan ) with monitoring $m / z, 195$.

Fig. 6. Analysis of LOX activity and Lox gene expression in olive fruit at different developmental stages. (A) Olives were collected at different maturation stages. LOX activity was measured from olives crude extracts using linoleic acid as substrate. Results are means of three determinations \pm SD. (B) Expression profile of LOX mRNA from olives was analysed by Northern blot with the LOXprobe1. (C) The membrane was stained with methylene blue $0.4 \%$ in sodium acetate $5 \mathrm{M}$ showing the $28 \mathrm{~S}$ and the $18 \mathrm{~S}$ ribosomal RNA (rRNA). 
Table 1 Kinetic parameters of purified recombinant olive LOX.

\begin{tabular}{lcccc}
\hline Substrate & $\mathrm{K}_{\mathrm{m}}(\mu \mathrm{M})$ & $\mathrm{V}_{\max }\left(\mathrm{nmol}^{-1} \mathrm{~s}^{-1}\right)$ & $\mathrm{k}_{\mathrm{cat}}\left(\mathrm{s}^{-1}\right)$ & $\mathrm{k}_{\text {cat }} / \mathrm{K}_{\mathrm{m}}\left(\mathrm{s}^{-1} \cdot \mu \mathrm{M}^{-1}\right)$ \\
\hline Linoleic acid & $174.94 \pm 7.20$ & $1.75 \pm 0.05$ & $48.61 \pm 0.27$ & 0.28 \\
Linolenic acid & $343.66 \pm 9.50$ & $1.72 \pm 0.07$ & $47.78 \pm 0.46$ & 0.14 \\
\hline
\end{tabular}

Values represent the mean of 3 independent replicates \pm standard deviation. 


\section{Fig. 1}

$\underset{\text { RACE product }}{\longrightarrow}$

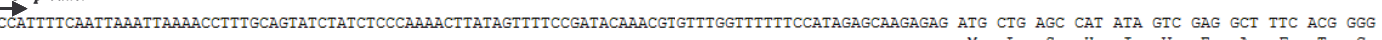
RT-PCR product 3

AAA AAT GAA GAA GAA AAT AAG AAG AAG ATC AAA GGG ACG GTA GTG AIG ATG AAA AAG AAT GTG TTA GAT TTC AAT GAT TTC GGT GGT TCA GIT CTT GAT CGA GTT CAT

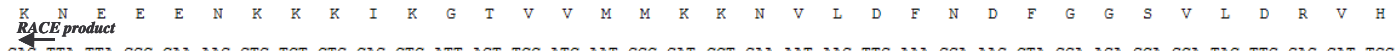

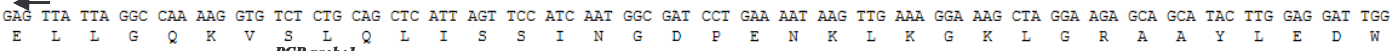

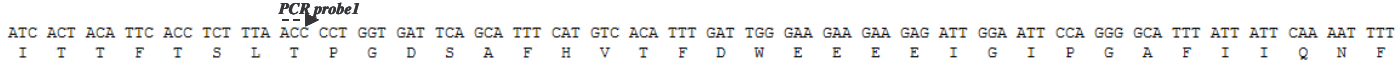
CAT CAT ACT GAA TIT TAC CIC AAG ACA CIT ACC CTT GAA GAT GIT CCT GGA CAT CAT GGT CCC ATC CAC ITT GIT TGC AAC TCT IGG GIT TAT CCT GCT GAA AAG TAC

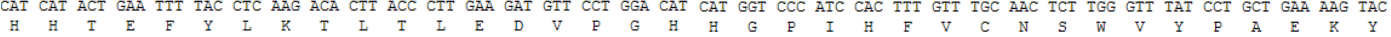
AAA ACA GAC CGC GTT ITC TIC ACA AAT AAG ACC TAT CIT CCA AGC GAA ACA CCA GAA CCA CTA GTC AAA TAC AGA GAA GAA GAA TTA GIT AAC TIG AGA GGA AAT GGA AGT GGA CAA CTT GAG GAA TGG GAC AGG GTA TAT GAC TAT GCT TAC TAC AAT GAT TTA GGA GAT CCT GAT AAA GGT TCC GAT TAT GCT AGG CCG GTT CTT GGA GGA TCC GTG GAG tAT CCG TAT CCT CGT AGg GGA AGA ACC GGT CGG CCT CCA ACA AAG ACA GAT CCG AAT TCT GAG AGC AGG ATT CCA CTG CTT ACG AGC TTA GAT ATT TAC ATT $\begin{array}{lllllllllllllllllllllllllllllllllllllll} & E & Y & P & Y & P & R & R & G & R & T & G & R & P & P & T & R & T & D & P & N & S & E & S & R & I & P & L & L & I & S & L & D & I & Y & I\end{array}$

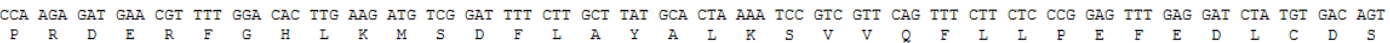
AIT CAC AAT GAG TIT GAC AGC TIC GAA GAT AIT CTT CAA ATC TAT GAA GGA GGT ITC AAG CTA CCA GAG GGT CCT TTG CTC AAA AAT ATT TIC GAA AAC AIT CCC TTT

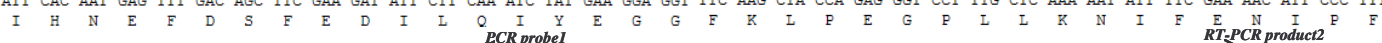

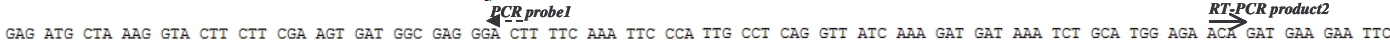

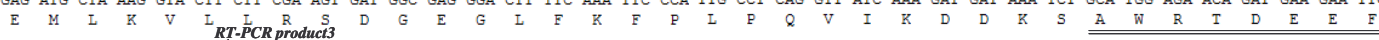

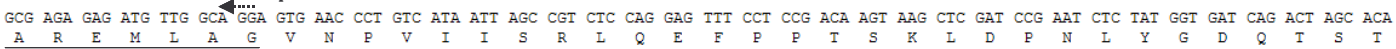
ATA TCA GGA GGC CAC ATA GAG AAT AAG TIG GAC GGA CTA ACA AIT GAC GAG GCA ATC AGG ACG AAC AAA CTG ITC ATA TTG AAC CAC CAC GAT GCA CTT ATG CCA TAT TTA AAG CGA ATA AAC TCG ACT ACC ACA AAG ACT TAT GCC TCA AGA ACT CTG CTT ITC TTG CAA AAA GAC GGA AGT TTG AAG CCA ITA GCA AIT GAA CTG AGC TTA CCT $\begin{array}{llllllllllllllllllllllllllllllllllll}I & K & R & I & N & S & T & T & T & K & T & Y & A & S & R & T & L & L & F & I & Q & K & D & G & S & I & K & P & I & A & I & E & I & S & I & P\end{array}$

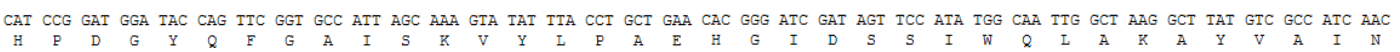

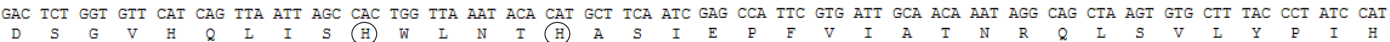
AAG CTT CTT CAT CCT CAC ITC CGA GAC ACA ATG AAC ATA AAT GCT GTG GGA CGA CAA ATC TTG ATT AAT GCT GGA GGA ATC CTT GAG GCG ACA GIT TTT CCG GCA AAA

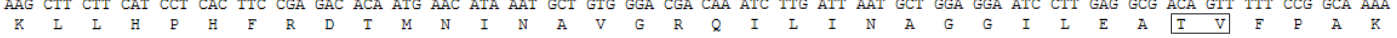
TAT ICC ATG GAA ATG TCA GCT GTG ATT TAT AAG GAC TGG GIT ITC ACA GAA CAA GGA CTC CCT GCT GAT CTA CIT AAG AGA GGA ATG GCA GIG GAC GAC TCG AAT TCA

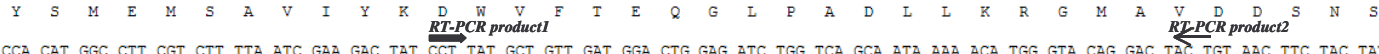

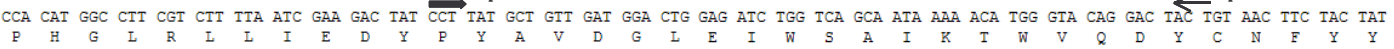
ACA ICA GAT AIT TTG GIT CAG AAA GAC GCT GAA CTC CAG TCC TGG TGG ACC GAA GIC CGG GAA AAG GGA CAT GGC GAC AAA AAG AAC GAG CCC TGG TGG CCT AAA ATG

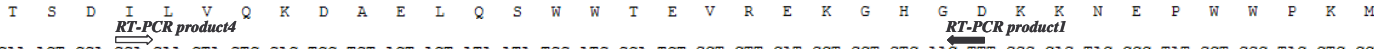
CAA ACT CGA GGA GAA CTA GTC GAC TCC TGT ACT ACT ATA ATA TGG ATG GCA TCT GCT CTT CAT GCT GCT GTC AAC TTT GGG CAG TAC CCC TAT GCT GGC TAC CTC CCG GTT CGT CCT ACC TTA AGT CGG AGG TTC ATG CCG GAA CCT GGA AAA CCC GAG TAT GAT GAG CTG AAG ACT AAC CCG GAT AAG GTT TTC CTG AAG ACA ATT ACT GCT CGG

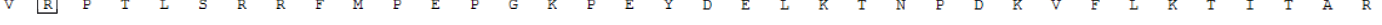

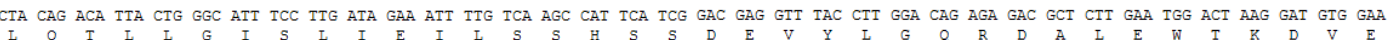

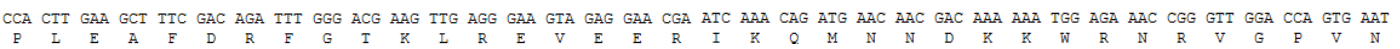
GIT CCA TAC ACT TTA CTT TAT CCT ACA AGT GAA GAG GGA CTT ACT GGC AAG GGA ATT CCC AAC AGT GTG TCA ATC TGA AGC TTA ICT GIT TAG GGA TAT TAC ATT TGT ATG CAT AIT CCT TAC ATT TCT ITT ACT GIT GAA GAA GGT ITG AIG AGT GAA AAT AGT AAT GCA GAT CGA TGT AIT CTC ATT TAC AAT AAT GAA TAA AAG TAA AAC ATA TAA CCA AAA AAA AAA AAA 
Fig. 2

A

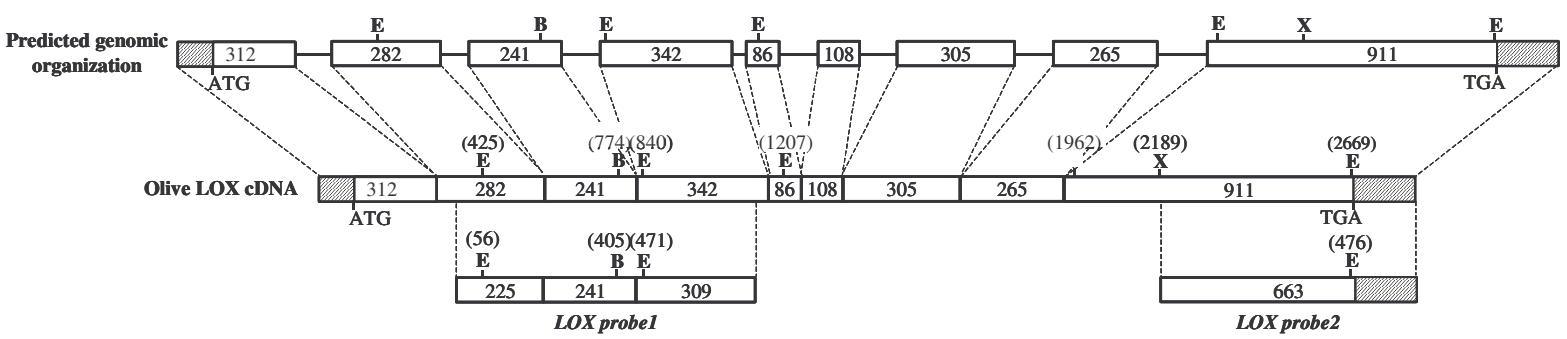

B

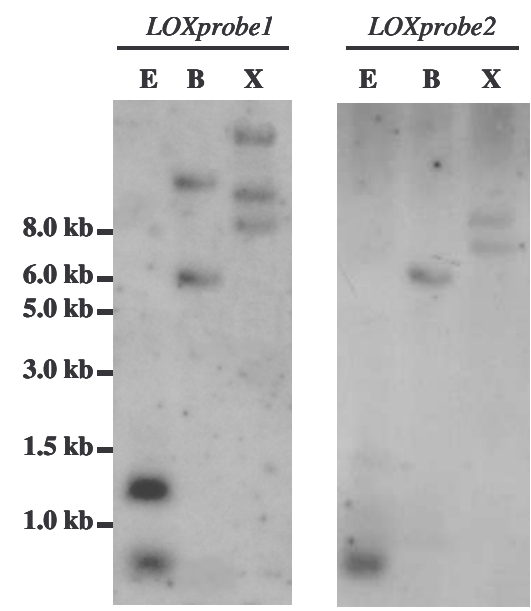


Fig. 3




Fig. 4




Fig. 5




Fig. 6

A

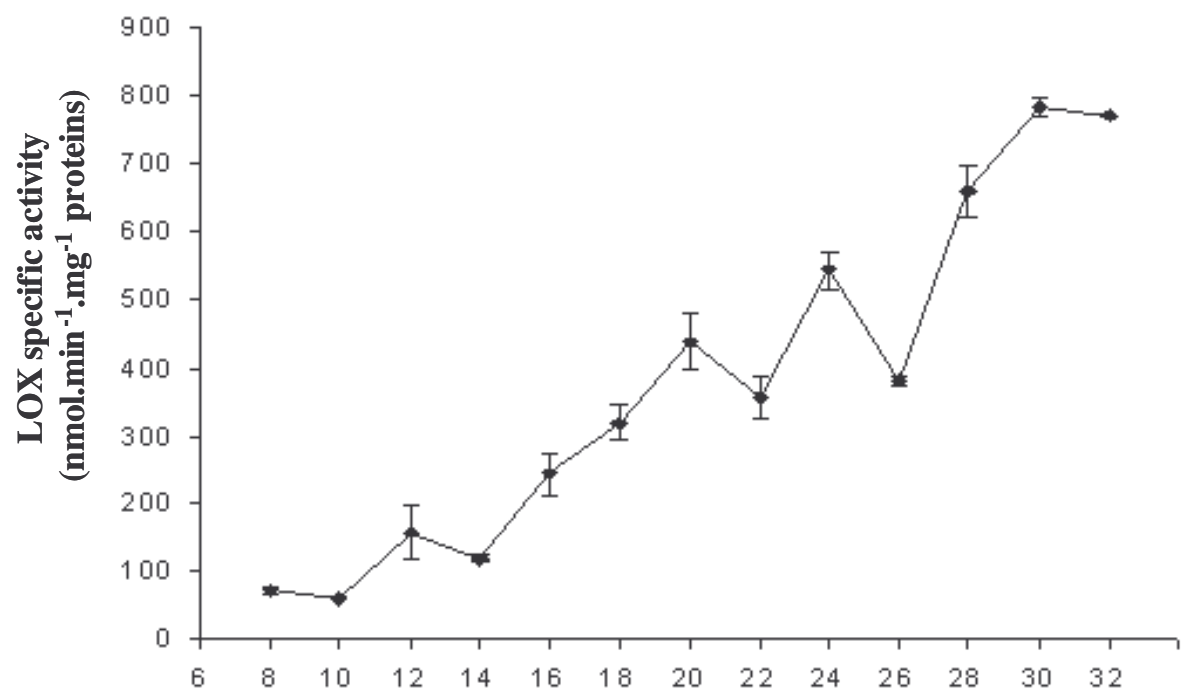

Weeks after flowering

B

$$
\begin{array}{lllllllllllll}
8 & 10 & 12 & 14 & 16 & 18 & 20 & 22 & 24 & 26 & 28 & 30 & 32
\end{array}
$$

9/13-LOX mRNA expression

C

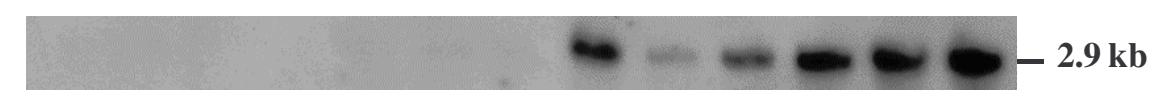

rRNA

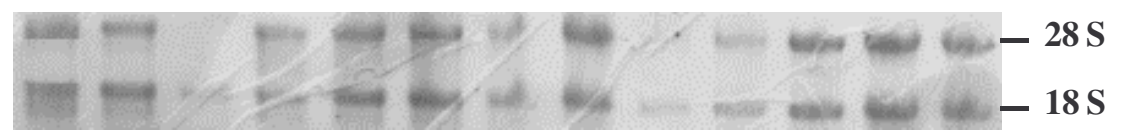

